The University of San Francisco

USF Scholarship: a digital repository @ Gleeson Library | Geschke Center

Nursing and Health Professions Faculty Research

and Publications

School of Nursing and Health Professions

2012

\title{
Horizontal Violence Among Hospital Staff Nurses Related to Oppressed Self or Oppressed Group
}

Christina Purpora

University of San Francisco, cmpurpora@usfca.edu

M A. Blegen

NA. Stotts

Follow this and additional works at: http://repository.usfca.edu/nursing_fac

Part of the Nursing Commons

\section{Recommended Citation}

Christina Purpora, Mary A. Blegen, Nancy A. Stotts. Horizontal Violence Among Hospital Staff Nurses Related to Oppressed Self or Oppressed Group. Journal of Professional Nursing - September 2012 (Vol. 28, Issue 5, Pages 306-314, DOI: 10.1016/

j.profnurs.2012.01.001)

This Article is brought to you for free and open access by the School of Nursing and Health Professions at USF Scholarship: a digital repository @ Gleeson Library | Geschke Center. It has been accepted for inclusion in Nursing and Health Professions Faculty Research and Publications by an authorized administrator of USF Scholarship: a digital repository @ Gleeson Library | Geschke Center. For more information, please contact repository@usfca.edu. 
Running head: HORIZONTAL VIOLENCE BETWEEN HOSPITAL STAFF

\author{
Horizontal Violence Between Hospital Staff Nurses Related to \\ Oppressed Self or Oppressed Group
}

\author{
Christina Purpora, RN, Ph.D \\ Assistant Professor \\ University of San Francisco \\ Mailing address: 2130 Fulton Street, San Francisco, CA 94117-1080 \\ Phone: (415) 503-0792 \\ Email: cmpurpora@usfca.edu \\ Mary A. Blegen, RN, Ph.D, FAAN \\ Professor Emerita \\ University of California, San Francisco \\ Nancy A. Stotts, RN, Ed.D, FAAN \\ Professor Emerita \\ University of California, San Francisco
}




\begin{abstract}
Horizontal violence among nurses is recognized as a major problem in hospitals; however, the origins and effects on patient care have not been studied. This study described the incidence of horizontal violence among hospital staff registered nurses (RNs) and tested two hypotheses about the social origins of this behavior. A random sample of 175 hospital staff RNs drawn from the California Board of Registered Nursing's mailing list was surveyed. Horizontal violence was reported by $21.1 \%(n=37)$ of participating nurses. Hypotheses were supported. Findings suggested (1) a positive relationship between beliefs consistent with an oppressed self and horizontal violence $(\mathrm{r}=.434, \mathrm{p}<.05)$ and $(2)$ a positive relationship between beliefs consistent with those of an oppressed group and horizontal violence $(r=.453, \mathrm{p}<.05)$. A change in the oppressive social structure of hospitals may be needed to truly address horizontal violence in the best interest of the quality and safety of patient care.
\end{abstract}




\section{Introduction}

Horizontal violence is injurious behavior aimed by one worker toward another who is of equal status within a hierarchy that seeks to control the person by disregarding and diminishing their value as a human being (Blanton, Lybecker, \& Spring, 1998). Displays of horizontal violence include calling coworkers demeaning names; using words, tone of voice, or body language that humiliates or ridicules them; belittling their concerns; and pushing them or throwing things (Blanton et al., 1998). Although a number of terms are used to label harmful behavior between nurses including aggression (Farrell, 1997, 1999; Farrell, Bobrowski \& Bobrowski, 2006), bullying, (Johnson \& Rea, 2009; Simons, 2009), lateral violence (Griffin, 2004; Stanley, Martin, Michel, Welton, \& Nemeth 2007), and verbal abuse (Cox, 1991a; Rowe \& Sherlock, 2005, Sofield \& Salmond, 2003; Ulrich et al., 2006), horizontal violence was used in this study. The other terms are considered forms of horizontal violence.

The reported incidence of horizontal violence in hospitals varies from $17.6 \%$ to $75 \%$ (Farrell, 1997, 1999; Farrell, Bobrowski \& Bobrowski, 2006; Johnson \& Rea, 2009; Simons, 2009; Griffin, 2004; Stanley et al., 2007; Rowe \& Sherlock, 2005, Sofield \& Salmond, 2003; Ulrich et al., 2006). However, these percentages should be viewed cautiously given the challenges encountered during this review. First, horizontal violence was defined and measured differently across studies. Most investigators used a measure created or modified for their study with little or no evidence of reliability and validity. The most consistent information about incidence, 27.3\% (Johnson \& Rea, 2009) and 31\% (Simons, 2008), came from two studies that used the same measure, which had evidence of reliability and validity. Second, incidence was reported based on samples which included nurses working in roles that placed them within differing levels of the hospital hierarchy making comparison impossible across individual 
populations. Some samples included nurse managers and staff RNs. Nurse managers are generally perceived as having higher status within the hierarchy and therefore have more power than staff nurses (Duffy, 1995; McCall, 1996). The status of nurses, whether staff or managers, included in studies is an important consideration because by definition, horizontal violence occurs among those who share the same status in a hierarchy such as staff RNs raising the question of whether horizontal violence or some other type of negative interaction is being measured in samples that included nurses in differing roles within the hierarchy.

Empirical evidence of a link between horizontal violence and the quality and safety of patient care is an area of emerging science. Findings suggested that nurses perceived a link but few tested the relationship between the concepts (Cox, 1991b; McKenna, Smith, Poole, \& Coverdale, 2003; Rowe \& Sherlock, 2005). Only one study to date found that there was a perceived inverse relationship between horizontal violence and quality of care, as horizontal violence increased, the quality and safety of patient care decreased (Purpora, 2010). Research is needed to describe factors, such as oppression, assumed to influence the incidence of horizontal violence given the perceived impact on the quality and safety of patient care in the presence of horizontal violence. In oppression theory, horizontal violence is a symptom of a larger problem. This study describes the relationship between nurses' oppressed self or oppressed group beliefs and horizontal violence. That relationship is important to study because findings may open a dialogue about how to truly address horizontal violence within the social structure of hospitals in the best interest of patient care.

\section{Background}

Oppressed people live in various places around the world just as they have throughout human history. Being oppressed means living a life dominated by the values of others whose 
way of life is deemed right (Freire, 1970/2003). The oppressed internalize these values while minimizing their own. In the process they develop aversion for their own people and become aggravated with their situation, yet afraid of living life any other way. They may cope with their frustration by directing acts of violence toward one another, behavior known as "horizontal violence" in oppression theory (Freire, 1970/2003, p. 62).

Nurses are among people thought to be oppressed. The historical premise for this argument is that their practice is dominated by forces outside of the profession with higher status and power (Ashley, 1975; Reverby, 1987). In the late 1800s and early 1900s, women cared for patients in exchange for nurses' training in hospitals. The male physicians and administrators who ran those hospitals served their own interests by receiving remuneration for the nursing care provided by the women with little or no compensation to the women (Ashley, 1975; Reverby, 1987). Furthermore, nursing practice was labeled the work of women and the care they provided in the process of their work was valued less than services rendered by male physicians.

Nurses are no longer entirely educated in hospitals nor do they work for free. Nonetheless, more than 100 years later the notion that nursing is an oppressed profession remains relevant. Today, nurses still work in hospitals where they continue to bear much responsibility for the care of patients and, like their predecessors, they do so with a disproportionate lower power when compared to physicians and administrators (Garman, Leach, Spector, 2006). Still influenced by their multifaceted lives as woman and nurses doing the work historically done by women, their work related attitudes about themselves and women as a group are shaped by the dominant values they internalize (DeMarco, Roberts, Norris, \& McCurry, 2008). Although the idea that nursing is oppressed can be used for explaining negative behavior among them as horizontal violence (Keen, 1991; Roberts, 1983; Skillings, 1992, Sofield \& 
Salmond, 2003; Simons, 2008), empirical evidence of an association between the internalized dominant values nurses hold that are reflective of being oppressed in hierarchical institutions and the negative acts of horizontal violence has yet to be produced. This study begins to describe that relationship.

The internalized values nurses hold that reflect beliefs of an oppressed self was labeled "minimization of self" while those of an oppressed group was labeled "internalized sexism" (DeMarco, Roberts, Norris, \& McCurry, 2008, p. 299). Minimization of self is defined as an individual's feelings of low self worth that may stop them from speaking freely, making their thoughts known (DeMarco et al., 2008). Internalized sexism is defined as unfavorable beliefs a person holds about women overall and the behavior they engage in when in a group that negates the usefulness of what they seek to accomplish (DeMarco et al., 2008).

The horizontal violence and the quality and safety of patient care model in Figure 1 guided this study (Purpora, 2010). The concepts, internalized dominant values and horizontal violence were the focus of this analysis. Internalized dominant values and horizontal violence are concepts taken from Freire's (1970/2003) theory of oppression. In the model, internalized dominant values represent the work-related attitudes nurses hold about themselves and nursing in response to the oppressive hierarchal environments where they work. In such a work situation, nurses may feel frustrated as they strive to advocate for themselves and their practice in a healthcare system that has historically devalued their contribution to healthcare (Ashley, 1976; DeMarco et al., 2008; Reverby, 1987). Blanton et al., (1998) used Freire's (1970/2003) work as well as others to develop their definition of horizontal violence that differs from the violent acts described by Freire, but is useful, nonetheless, for explaining horizontal violence among nurses given the assumption they constitute an oppressed group. 


\section{Methods}

\section{Purpose}

This paper describes the incidence of horizontal violence among hospital staff RNs and tests for an association between their beliefs consistent with an oppressed self and horizontal violence and an oppressed group and horizontal violence. In addition, the study examined the relationship of horizontal violence with nurse and work characteristics. The aim of the study was to describe the relationship between nurses' beliefs about themselves and nursing as a group that are reflective of being oppressed and horizontal violence. Study hypotheses were: Hypothesis 1: There is a positive relationship between hospital staff RNs report of minimization of self (oppressed self) and horizontal violence and Hypothesis 2: There is a positive relationship between hospital staff RNs report of internalized sexism (oppressed group) and horizontal violence.

\section{Data Collection}

This cross-sectional model testing study is part of a larger study that described hospital staff RNs work related views of themselves, nursing as a group, and their interactions and relationships with other staff RNs, and quality of patient care (Purpora, 2010). Mailed and online surveys were used to collect data from a random sample of hospital staff nurses with active licenses in California (CA). The University of California, San Francisco's Committee on Human Research approved the study.

The list of all RNs licensed in CA was obtained from the California Board of Registered Nursing (CA BRN). This mailing list provided the names and addresses of the entire population of RNs with active licenses in the state ( $n=309,940$ as of January 26, 2010); but did not indicate their work setting. From this list a random sample of 3000 was selected to assure that a large 
enough pool of staff nurses working in hospitals would be included. Adapted from Dillman's (2007) five step Tailored Design method of survey administration, nurses were contacted up to three times. A postcard was mailed to all 3000 RNs inquiring about their interest in participating in the study. RNs were invited if they were working as staff nurses in hospitals and willing to share their views in an anonymous survey. If interested and eligible, they returned a supplied postcard indicating their preference to do so online or with a paper survey. In return they were sent an information sheet for the online survey or the paper survey, the paper survey, if that was their format of their choice, and a \$2 bill as a thank you gift. The information sheet explained that participation was voluntary and receipt of a survey by investigators represented consent. One week later, a reminder postcard was mailed to all who returned a postcard thanking them for completing a survey if they had and asking them to do so if they had not.

\section{Measures}

Internalized Dominant Values. The 12 item Nurses Workplace Scale (NWS) measured attitudes consistent with those of an oppressed self and oppressed group (DeMarco, et al., 2008). The items comprised two subscales. Minimization of Self (oppressed self) measured attitudes held that prevents a person from openly stating their opinion including "prefaced statements with phrases such as I know this is a really stupid question " and "changed your story according to the professional audience" (DeMarco et al., 2008, p.299). Internalized Sexism (oppressed group) measured unfavorable beliefs held about women's behavior in groups that undermine their being successful in what they do including "said it's really hard to work with a bunch of women" and "believed that men have more natural leadership ability than women" (DeMarco et al., 2008 p.299). Participants indicated how often items applied to them at work using a response scale with the range, $1=$ never to $5=$ always. Mean scores ranged from 1-5, the higher the score the 
more often attitudes reflected internalized sexism or minimization of self. DeMarco et al. (2008) provided evidence of adequate reliability and validity.

Horizontal Violence. Einarsen, Hoel, \& Notelaers' (2009) Negative Acts QuestionnaireRevised (NAQ-R) measured horizontal violence. The NAQ-R is the English language version of the original Norwegian Negative Acts Questionnaire (NAQ) created in the United Kingdom (UK). The NAQ-R consists of 22 negative behaviors that indirectly measured bullying, a form of horizontal violence that occurs frequently (Simons, 2008). Items included "having your opinions and views ignored", "spreading of gossip or rumors about you," threats of violence or physical abuse or actual abuse" (Einarsen et al., 2009, p. 32). The negative act "being exposed to an unmanageable workload" was removed from this analysis. In previous work, this item was frequently chosen and thought to be more directly related to the current workplace conditions than to horizontal violence or bullying (Johnson \& Rea, 2008).

Participants indicated how frequently they experienced each negative act in the last six months with the response scale that ranged from $1=$ never to 5=daily. In addition to examining the frequency of each item, mean scores for the entire 21 item scale were calculated and ranged from $1-5$, the higher the score the more frequently negative acts were experienced at work. Previous work provided evidence of appropriate reliability and validity (Einarsen et al., 2009; Lutgen-Sandvik, Tracy, \& Alberts, 2007; Johnson \& Rea, 2009; Simons, 2008).

Demographics. Demographic continuous variables included age, years of experience working as an RN in a hospital, and average number of hours worked. Categorical variables included gender, race, basic RN education, highest degree held, type and size of hospital, and clinical area. 


\section{Data Analysis}

Statistical Package for the Social Sciences (SPSS) version 16.0 for Windows (2007) was used to analyze data. Once data were cleaned, minimum and maximum values, means, standard deviation $(\mathrm{SD})$ or frequencies were used to describe the sample. Frequencies described the incidence of horizontal violence. Mean scores for the NWS subscales - internalized sexism and minimization of self- and the 21 item NAQ-R were calculated. Cronbach's alpha measured the reliability of each scale. Pearson product moment correlation coefficients and hierarchical multiple regressions explored relationships among variables. An alpha level of .05 was preset.

\section{Findings}

Two hundred thirty four nurses returned postcards indicating their interest in participating and their survey format preference: 215 surveys were sent to participants as 19 did not meet inclusion criteria. One hundred seventy-five surveys, 84 on paper and 91 on-line, were returned. The response rate was calculated by subtracting the following amounts from the initial 3000 nurses randomly selected from the CA BRN mailing list: $20 \%$ whose addresses were estimated to be outdated by the researchers $(n=600), 13 \%$ for nurses not working $(n=312), 35.6 \%$ for nurses who do not work in hospitals $(n=854)$, and from the remaining $1234,24.4 \%(n=301)$ of nurses working in hospitals but not as staff (Spetz, Keane \& Herrera, 2008). Therefore the largest possible number of nurses fitting the inclusion criteria was likely 933 and the response rate was $18.8 \%(175 / 933)$.

\section{Sample}

As shown in Table 1, the demographic profile of the sample in this study was very similar to the population of CA nurses, making the study sample representative based on race, gender, age, basic RN education, highest degree held, clinical area, and average number of hours 
worked. The mean number of years working as an $\mathrm{RN}$ in a hospital was 16 years $(\min =1$, $\max$ 45). Most nurses worked in a 100-300 bed hospital $(n=84,48 \%)$ in the community hospital setting $(\mathrm{n}=114,65 \%)$.

\section{Incidence}

Participants were asked how frequently they experienced negative acts from another staff RNs at work. The frequencies and percentages of these behaviors are displayed in Table 2. Based on the criterion of two or more negative acts experienced weekly or daily in the last six months, the incidence of horizontal violence was $21.1 \%(n=37)$. Being ordered to do work below level of competence $(12.6 \% ; \mathrm{n}=22)$, being given tasks with unreasonable deadlines $(11.4 \% ; \mathrm{n}=20)$, having opinions and views ignored $(9.9 \% ; n=17)$, and being ignored or excluded $(9.2 \% ; n=16)$ were the negative acts reported most often. Those reported with the least frequency were intimidating behavior, finger-pointing, invasion of personal space, shoving, blocking/barring the way $(1.7 \% ; n=3)$, practical jokes $(1.7 \% ; n=3)$, having allegations made $(1.7 \% ; n=3)$, and threats of violence or physical abuse or actual abuse $(0.6 \% ; n=1)$.

\section{Research Variables by Nurse and Work Characteristics}

Table 3 displays mean scores of internalized sexism, minimization of self, and horizontal violence by nurse and work characteristics: the reliability of the measures was also included. Cronbach's alpha values in this study are similar to those from previous work indicating evidence of reliability in different populations. In this study, Cronbach's alpha of .92 for the 21 item NAQ-R was good. Though no known studies report internal consistency of the 21 item scale, the value is similar to those reported for the 22 item scale. The internal consistency of the internalized sexism, .87 and minimization of self, .79 were strong and consistent with evidence of reliability provided by Demarco et al. (2008), .74 and .80 respectively. 
There were few statistically significant differences by demographic and employment characteristics. Females reported higher minimization of self (oppressed self beliefs) than males though there was no difference in internalized sexism (oppressed group beliefs). Nurses who did not hold a BSN as their basic $\mathrm{RN}$ education reported more horizontal violence than those educated with BSN or higher. RNs working in other clinical areas reported more horizontal violence than those working in intensive care or non intensive care clinical areas such as medical-surgical. Other clinical areas included geriatrics, mental health, and those nurses who did not have a clinical specialty. Race, highest degree held, and size and type of hospital showed no statistically significant effects.

\section{Correlation}

Pearson's r was used to describe relationships among continuous variables: age, years of experience working in a hospital as an $\mathrm{RN}$, average number of hours worked per week, horizontal violence, internalized sexism and minimization of the self (Table 4). The only statistically significant correlations found were among the three scales and between age and years of experience.

\section{Hypothesis Testing}

Based on these bivariate findings, demographic variables for inclusion in the regression model included gender, basic RN education, and clinical area. Years of experience was included based on previous work that nurses with less years of experience would report more horizontal violence (McKenna et al., 2003; Simons, 2009). Variables with more than three response choices were collapsed into two or three groups: basic RN education into non-BSN and BSN or higher, and clinical area into intensive care, non-intensive care, and other. Intensive care was the 
reference group for dummy coded clinical area comparing non-intensive care to intensive care and other to intensive care.

Hypothesis 1: There is a positive relationship between hospital staff RNs report of minimization of self (oppressed self) and horizontal violence and Hypothesis 2: There is a positive relationship between hospital staff RNs report of internalized sexism (oppressed group) and horizontal violence. A significant positive correlation was found between minimization of self and horizontal violence and between internalized sexism and horizontal violence (Table 4). As minimization of self increased and internalized sexism increased, so did horizontal violence in both bivariate and multivariate analyses. In the multivariate analysis gender, basic RN education, and years of experience were not significant predictors of horizontal violence but minimization of self, internalized sexism and clinical area were (Table 5). For every one unit increase in minimization of self score, there was a corresponding .288 increase in horizontal violence score, controlling for the other variables in the model $(\mathrm{p}<.05)$. For every one unit increase in internalized sexism score, there was a corresponding .234 increase in horizontal violence score, controlling for the other variables in the model $(\mathrm{p}<.05)$. Comparing clinical area, nurses on non-intensive care units experienced less horizontal violence (B - .209) controlling for all other variables in the model $(\mathrm{p}<.05)$.

\section{Discussion}

Nurses in this study reported a $21.1 \%(n=37)$ incidence of horizontal violence which is lower than the $31 \%$ who reported being bullied in Massachusetts (Simons, 2008) and the 27.3\% in Washington (Johnson \& Rea, 2009) using the same tool. The most frequently occurring acts varied between verbal and non-verbal acts across studies but the least frequent negative act, threats of or actual physical abuse $(n=1 ; 0.6 \%)$ was a consistent finding with one study of 
American workers in various industries (Lutgen-Sandvik et al., 2007) and two studies in nursing (Simons, 2008; Johnson \& Rea, 2009). The notion that horizontal violence is manifested verbally and non-verbally but rarely as physical acts of violence was raised in three studies in nursing, two in Australia (Farrell, 1997; 1999) and another in New Zealand (McKenna et al., 2003). This idea and the review of literature bring into question how horizontal violence is operationalized. Further research is needed to explore and compare different measurement options.

No relationship was found between horizontal violence and age, gender, or race. Likewise, Johnson and Rea (2009) found no relationship with these variables. Preliminary analysis revealed significant mean differences with gender, education and clinical area. However, multivariate analysis demonstrated that internalized sexism, minimization of self and clinical area predicted horizontal violence but gender and education did not. Although there is concern that new graduate nurses experience more horizontal violence than those with more experience, previous work and this study did not provide evidence of a relationship (Simons, 2009). Lack of evidence of a relationship between horizontal violence and nurses' demographic profile suggests that horizontal violence has less to do with their demographic and more to do with how they view themselves and nursing and the clinical area where they work. This finding is a curious one given that people are often oppressed based demographics such as gender and race (Ehrenreich \& English, 2005; Freire, 1970/2003; Fanon, 1963). Moreover, this finding may also not be surprising given the argument that nurses beliefs about themselves and nursing are shaped by the multifactorial influences including working in hierarchical systems rather than their individual characteristics (Demarco et al., 2008). Further research is needed to describe the influence of demographics on horizontal violence. 
This study supported the two hypotheses tested. As nurses internalized beliefs about themselves or women as a group consistent with being oppressed increased, so did horizontal violence. The relationship can be explained in that the beliefs nurses hold that reflect being oppressed represents the work situation of nurses practicing in hierarchical institutions that shape their behavior beliefs and feelings about themselves or nursing and horizontal violence corresponds to the negative behavior they are at risk for experiencing. These beliefs and feelings undermine their success as a group and prevent individual nurses from making their opinions known and championing their practice (DeMarco et al., 2008). Furthermore, these beliefs and feelings are associated with and predict horizontal violence. This study provides empirical evidence of a link between these concepts previously theorized. More research is needed to confirm that a relationship exists between oppressed self or oppressed group beliefs and horizontal violence across populations of staff RNs working in hospitals in other states.

This study has implications for nursing education and for practice. One study suggested behavioral techniques for use by individuals to respond to perpetrators of horizontal violence (Griffin, 2004). Nursing organizations call for zero tolerance of the behavior (American Association of Critical Care Nurses, 2004; Center for American Nursing, 2008). Zero tolerance is a start but ultimately not enough. DeMarco et al (2008) posit that nurses may encounter barriers in the institutions where they work as they strive to advocate for themselves and their practice. The first step toward addressing change is to provide evidence that the social structure of hospitals has a negative impact on people working there and on those receiving care in them. Further research is needed including intervention research to identify strategies that help individual nurses effectively cope with horizontal violence and to describe barriers within the 
social structure of hospitals that prevent nurses from advocating for themselves and their practice, a possible source of frustration that may put nurses at risk for horizontal violence.

\section{Study Limitations}

The response rate to this study was low at $18.8 \%$. Nine hundred and thirty three of the 3000 randomly selected RNs in CA were estimated as eligible to participate, yet 175 did. Not known is how the views of the remaining 758 might have impacted study findings. Some researchers suggest that factors such as the stressful hospital work environment (Vessey, DeMarco, Gaffney \& Budin, 2009; Sofield \& Salmond, 2003; Stanley et al., 2007) and dysfunctional work relationships (Vessey et al., 2009) contribute to the incidence of horizontal violence. Factors not controlled for in this study could predict horizontal violence. Other factors not controlled for are important to consider when concluding that the independent variables internalized sexism and minimization of self have relationships with horizontal violence. Being oppressed is one factor that shapes nurses behavior and their feelings and beliefs about themselves and nurses as a group. However, stress and negative work relationships are others and their influence on the relationship is not known. Causal relationships between variables in cross-sectional studies cannot be ascertained; further work is needed to establish causal relationships.

\section{Conclusion}

This paper described the incidence of horizontal violence among hospital staff RNs and tested for an association between the beliefs nurses hold that are consistent with an oppressed group or self and horizontal violence. In addition, the relationship of horizontal violence with nurse and work characteristics was examined. This study provides beginning empirical evidence to support what nurse authors and researchers have postulated; nurses working in oppressive 
hierarchical hospitals are at risk for horizontal violence, however, this is one study. More research is needed to gather empirical evidence in different populations of staff RNs and to create strategies that individual nurses can use to manage horizontal violence. Further, a change in the oppressive social structure of hospitals many be needed to truly address horizontal violence in the best interest of quality of patient care. 


\section{References}

American Association of Critical-Care Nurses. (2004). Zero tolerance for abuse. Retrieved January 7, 2010 from http://www.aacn.org/WD/Practice/Docs/Zero_Tolerance_for_Abuse.pdf

Ashley, J. (1976). Hospitals, paternalism, and the role of the nurse. New York: Teachers College Press.

Blanton, B.A., Lybecker, C., \& Spring, N.M. (1998, July). A horizontal violence position statement. Retrieved December 3, 2009 from http://proactivenurse.com/index.php?option=com_content $\&$ Itemid=22\&id=83

Center for American Nurses. (2008). Lateral Violence and bullying in the workplace. Retrieved January 7, 2010 from http://www.can.affiniscape.com/associations/9102/files/Position\%20StatementLateral\%2 0Violence\%20and\%20Bullying.pdf

Cox, H. (1991a). Verbal abuse nationwide, part I: Oppressed group behavior. Nursing management, 22(3), 66-69.

Cox, H. (1991b). Verbal abuse nationwide, part II: Impact and modifications. Nursing management, 22(2), 32-35.

DeMarco, R., Roberts, S.J., Norris, A., \& McCurry, M. K. (2008). The development of the nurse workplace scale: Self-advocating behaviors and beliefs in the professional workplace. Journal of Professional Nursing, 24(5), 296-301.

Dillman, D. (2007). Mail and Internet Surveys the Tailored Design Method (2 ${ }^{\text {nd }}$ ed.). Hoboken, NJ: Wiley.

Duffy, E. (1995). Horizontal violence: A conundrum for nursing. Collegian, 2(2), 5-9, 12-16. 
Ehrenreich, B. \& English, D. (2005) For her own good; Two centuries of the experts' advise to women $\left(2^{\text {nd }}\right.$ ed.). New York: Random House.

Einarsen, S., Hoel, H., \& Notelaers, G. (2009). Measuring exposure to bullying and harassment at work: Validity, factor structure and psychometric properties of the negative acts questionnaire-revised. Work \& Stress, 23(1), 24-44.

Fanon, F. (1963). The wretched of the earth. New York: Grove Press.

Farrell, G. A. (1997). Aggression in clinical settings. Journal of Advanced Nursing, 25, 501-508.

Farrell, G. A. (1999). Aggression in clinical settings: nurses' views - a follow up study. Journal of Advanced Nursing, 29, 532-541.

Farrell, G.A., Bobrowski, C., \& Bobrowski, P. (2006). Scoping workplace aggression in nursing: Findings from an Australian study. Journal of Advanced Nursing, 55(6), 778-787.

Freire, P. (2003). Pedagogy of the oppressed (30 ${ }^{\text {th }}$ anniversary ed.). New York: The Continuum International Publishing Group. (Original work published 1970).

Garman, A. N., Leach, D. C., \& Spector, N. (2006). Worldviews in collision: Conflict and collaboration across professional lines. Journal of Organizational Behavior, 27, 829-849.

Griffin, M. (2004). Teaching cognitive rehearsal as a shield for lateral violence: An intervention for newly licensed nurses. The Journal of Continuing Education in Nursing, 35(6), 257263.

Johnson, S. L., \& Rea, R. E. (2009). Workplace bullying concerns for nurse leaders. The Journal of Nursing Administration, 39(2), 84-90.

Keen, P. (1991). Caring for ourselves. In R. M. Neil \& R. Watts (Eds.), Caring and nursing: Exploration in feminist perspectives (pp. 173-188). New York: National League for Nursing. 
Lutgen-Sandvik, P., Tracy, S. J., \& Alberts, J. K. (2007). Burned by bullying in the workplace: Prevalence, perception, degree and impact. Journal of Management Studies, 44(6), 837861.

McCall, E. (1996). Horizontal violence in nursing: The continued silence. The Lamp, 53(3), 2831.

McKenna, B. G., Smith, N. A., Poole, S. J., \& Coverdale, J. H. (2003). Horizontal violence: Experiences of registered nurses in their first year of practice. Journal of Advanced Nursing, 42(1), 90-96.

Purpora, C.. (2010). Horizontal violence among hospital staff nurses and the quality and safety of patient care. Ph.D. dissertation, University of California, San Francisco, United States -- California. Retrieved November 27, 2010, from Dissertations \& Theses @ University of California.(Publication No. AAT 3426213).

Reverby, S. M. (1987). Ordered to care: The dilemma of American nursing, 1850-1945. New York: Cambridge University Press.

Roberts, S. J. (1983). Oppressed group behavior: Implications for nursing practice. Advances in Nursing Science, 5(4), 21-30.

Rowe, M. M., \& Sherlock, H. S. (2005). Stress and verbal abuse in nursing : Do burned out nurses eat their young? Journal of Nursing Management, 13, 242-248.

Simons, S. (2008). Workplace bullying experienced by Massachusetts registered nurses and the relationship to intention to leave the organization. Advances in Nursing Science, 31(2), E48-E59.

Skillings, L. N. (1992). Perceptions and feelings of nurses about horizontal vioelcne as an expression of oppressed group behavior. In J. L. Thompson, D. D. Allen, \& L. 
Rodrigues-Fisher (Eds.), Critique, resistance, and action (pp. 167-185). New York: National League for Nursing Press.

Sofield, L., \& Salmond, S. W. (2003). Workplace violence: A focus on verbal abuse and intent to leave the organization. Orthopaedic Nursing, 22(4), 274-283.

Spetz, J., Keane, D., \& Herrera, C. (2009). California board of registered nursing 2008 survey of registered nursing. University of California, San Francisco School of Nursing and Center for the Health Professions.

Stanley, K. M., Martin, M. M., Michel, Y., Welton, J. M., \& Nemeth, L. S. (2007). Examining lateral violence in the nursing workforce. Issues in Mental Health Nursing, 28, 12471265.

Ulrich, B. T., Lavandero, R., Hart, K. A., Woods, D., Leggett, J., \& Taylor, D. (2006). Critical care nurses' work environments: A baseline status report. Critical Care Nurse, 26(5), 4657.

Vessey, J. A., DeMarco, R. F., Gaffney, D. A., Budin, W. C. (2009). Bullying of staff registered nurses in the workplace: A preliminary study for developing personal and organizational strategies for transforming of hostile to health workplace environments. Journal of Professional Nursing, 25(5), 299-306. 


\section{Acknowledgements}

This work was supported by funding from the University of California, San Francisco (UCSF) School of Nursing's Center for Patient Safety and Century Club funds, the Gordon and Betty Moore Foundation's Betty Irene Moore Doctoral Fellowship, the UCSF Graduate Division Graduate Student Research Award, the Sigma Theta Tau International Alpha Eta Chapter Research Award.

The authors thank the nurses who participated in the study for without them, this work wouldn't be. 
Table 1

Comparison of Study Sample to CA BRN 2008 Survey of California Registered Nurses

\begin{tabular}{lll}
\hline Variable & Study Sample $(\mathrm{n}=175)$ & CA BRN $(\mathrm{n}=5440)$ \\
\hline Age & 46.2 years & 47.1 years \\
Gender & $91 \%$ Female & $86 \%$ Female \\
Race & $61 \%$ Caucasian & $59 \%$ Caucasian \\
Basic RN Education & $41 \%$ Associate & $46 \%$ Associate \\
Highest degree Held & $50 \%$ Bachelor's & $42 \%$ Bachelor's \\
Clinical Area & $21 \%$ Medical-Surgical & $13.1 \%$ Medical-Surgical \\
Average number of hours worked & 35.6 hours & 36.5 hours
\end{tabular}

Note. CA BRN demographic variables from "California board of registered nursing 2008 survey of registered nurses," by the University of California, San Francisco: J. Spetz, D. Keane, and C. Herrera, 2009. 
Table 2

Frequency and Percentages of Individual Negative Acts $(\mathrm{n}=175)$

\begin{tabular}{|c|c|c|c|}
\hline Negative Act & $\begin{array}{l}\text { Weekly, } \\
\mathrm{n}(\%)\end{array}$ & $\begin{array}{l}\text { Daily, } \\
\mathrm{n}(\%)\end{array}$ & $\begin{array}{l}\text { Total } \\
\mathrm{n}(\%)\end{array}$ \\
\hline Someone withholding information that affects your performance & $7(4.0)$ & $3(1.7)$ & $10(5.7)$ \\
\hline Being humiliated or ridiculed in connection with your work & $5(2.9)$ & $2(1.1)$ & $7(4.0)$ \\
\hline Being ordered to do work below your level of competence & $10(5.7)$ & $12(6.9)$ & $22(12.6)$ \\
\hline $\begin{array}{l}\text { Having key areas of responsibility removed or replaced with more } \\
\text { trivial tasks }\end{array}$ & $5(2.9)$ & $8(4.6)$ & $13(7.5)$ \\
\hline Spreading of gossip and rumors about you & $8(4.6)$ & $3(1.7)$ & $11(6.3)$ \\
\hline Being ignored or excluded or isolated from others & $8(4.6)$ & $8(4.6)$ & $16(9.2)$ \\
\hline $\begin{array}{l}\text { Having insulting or offensive remarks made about your person, } \\
\text { attitudes, private life }\end{array}$ & $4(2.3)$ & $5(2.9)$ & $9(5.2)$ \\
\hline $\begin{array}{l}\text { Being shouted at or being the target of spontaneous anger (or } \\
\text { rage) }\end{array}$ & $6(3.4)$ & 0 & $6(3.4)$ \\
\hline $\begin{array}{l}\text { Intimidating behavior, finger-pointing, invasion of personal space, } \\
\text { shoving, blocking/barring the way }\end{array}$ & $2(1.1)$ & $1(0.6)$ & $3(1.7)$ \\
\hline Hints you should quit your job & $4(2.3)$ & 0 & $4(2.3)$ \\
\hline Repeated reminders of your errors or mistakes & $5(2.9)$ & $1(0.6)$ & $6(3.5)$ \\
\hline Being ignored or facing a hostile reaction when you approach & $7(4.0)$ & $2(1.1)$ & $9(5.1)$ \\
\hline Persistent criticism of your work or effort & $5(2.9)$ & $1(0.6)$ & $6(3.5)$ \\
\hline Having your opinions and views ignored & $11(6.3)$ & $6(3.4)$ & $17(9.9)$ \\
\hline Practical jokes carried out by people you don't get along with & $2(1.1)$ & $1(0.6)$ & $3(1.7)$ \\
\hline $\begin{array}{l}\text { Being given tasks with unreasonable or impossible targets or } \\
\text { deadlines }\end{array}$ & $11(6.3)$ & $9(5.1)$ & $20(11.4)$ \\
\hline Having allegations made against you & $3(1.7)$ & 0 & $3(1.7)$ \\
\hline Excessive monitoring of your work & $4(2.3)$ & $7(4.0)$ & $11(6.3)$ \\
\hline $\begin{array}{l}\text { Pressure not to claim something you are entitled to: sick or } \\
\text { vacation time, travel expenses }\end{array}$ & $9(5.1)$ & $4(2.3)$ & $13(7.4)$ \\
\hline Being subject of excessive teasing and sarcasm & $3(1.7)$ & $1(0.6)$ & $4(2.3)$ \\
\hline Threats of violence or physical abuse or actual abuse & $1(0.6)$ & 0 & $1(0.6)$ \\
\hline
\end{tabular}

Negative Acts Questionnaire-Revised (NAQ-R) items from "Measuring exposure to bullying and harassment at work: Validity, factor structure and psychometric properties of the negative acts questionnaire-revised," by S. Einarsen, H. Hoel, and G. Notelaers, 2009, Work and Stress, 23(1), p. 32 . 
Table 3

Means of Research Variables by Nurse and Work Characteristics and Reliability of Measures

Internalized Minimization of Self Horizontal Violence

Sexism (7 items) (21 items)

(5 items)

\begin{tabular}{|c|c|c|c|}
\hline Overall Mean (SD) & $1.87(.788)$ & $2.18(.612)$ & $1.52(.525)$ \\
\hline Cronbach's alpha & .87 & .79 & .92 \\
\hline \multicolumn{4}{|l|}{ Gender } \\
\hline Female $(n=159)$ & 1.88 & $2.21 *$ & 1.51 \\
\hline Male $(n=13)$ & 1.89 & 1.82 & 1.48 \\
\hline \multicolumn{4}{|l|}{ Race } \\
\hline Caucasian $(\mathrm{n}=107)$ & 1.80 & 2.20 & 1.52 \\
\hline Non-Caucasian $(\mathrm{n}=66)$ & 1.99 & 2.15 & 1.50 \\
\hline \multicolumn{4}{|l|}{ Basic RN education } \\
\hline Non-BSN (n=89) & 1.93 & 2.26 & $1.60 *$ \\
\hline BSN or above $(n=84)$ & 1.81 & 2.10 & 1.42 \\
\hline \multicolumn{4}{|l|}{ Highest Degree Held } \\
\hline Non-BSN $(\mathrm{n}=58)$ & 1.90 & 2.22 & 1.61 \\
\hline BSN or above $(n=115)$ & 1.86 & 2.17 & 1.46 \\
\hline \multicolumn{4}{|l|}{ Type of Hospital } \\
\hline \multicolumn{4}{|l|}{ Community } \\
\hline Yes $(n=114)$ & 1.96 & 2.22 & 1.53 \\
\hline No $(n=58)$ & 1.71 & 2.10 & 1.48 \\
\hline \multicolumn{4}{|l|}{ Teaching } \\
\hline Yes $(n=66)$ & 1.79 & 2.23 & 1.50 \\
\hline No $(n=106)$ & 1.93 & 2.15 & 1.53 \\
\hline \multicolumn{4}{|l|}{ Government } \\
\hline Yes $(n=7)$ & 1.51 & 1.76 & 1.54 \\
\hline No $(n=165)$ & 1.89 & 2.20 & 1.51 \\
\hline \multicolumn{4}{|l|}{ Size of Hospital } \\
\hline$<100$ beds $(n=20)$ & 1.88 & 2.28 & 1.67 \\
\hline $100-300(n=84)$ & 1.82 & 2.14 & 1.50 \\
\hline$>300(n=65)$ & 1.92 & 2.23 & 1.50 \\
\hline \multicolumn{4}{|l|}{ Clinical Area } \\
\hline Intensive care $(n=69)$ & 1.92 & 2.17 & 1.63 \\
\hline Non-intensive care $(n=79)$ & 1.78 & 2.18 & 1.38 \\
\hline Other $(n=22)$ & 1.94 & 2.23 & $1.66 * *$ \\
\hline
\end{tabular}

$* \mathrm{p}<05, * * \mathrm{p}<.01$ 
Table 4

Correlation of Research and Demographic Variables

\begin{tabular}{|c|c|c|c|c|c|c|}
\hline & $\begin{array}{c}\text { Internalized } \\
\text { Sexism }\end{array}$ & $\begin{array}{c}\text { Minimization of } \\
\text { Self }\end{array}$ & $\begin{array}{l}\text { Horizontal } \\
\text { Violence }\end{array}$ & Age & Years & Hours \\
\hline $\begin{array}{l}\text { Internalized } \\
\text { Sexism }\end{array}$ & 1.0 & & & & & \\
\hline $\begin{array}{l}\text { Minimization of } \\
\text { Self }\end{array}$ & $.262 * *$ & 1.0 & & & & \\
\hline $\begin{array}{l}\text { Horizontal } \\
\text { Violence }\end{array}$ & $.453 * *$ & $.434 * *$ & 1.0 & & & \\
\hline Age & .143 & .012 & .153 & 1.0 & & \\
\hline $\begin{array}{l}\text { Years of } \\
\text { Experience }\end{array}$ & .141 & -.014 & .085 & $.776 * *$ & 1.0 & \\
\hline Hours Worked & .046 & .089 & .124 & .011 & -.070 & 1.0 \\
\hline
\end{tabular}

Note: Years $=$ years of experience working as an RN in the hospital, Hours=number of hours worked per week.*p<.05; **p<.01 
Table 5

Summary of Hierarchical Regression Analyses for Variables Predicting Horizontal Violence $(n=167)$

\begin{tabular}{|c|c|c|c|c|}
\hline Source & $\mathrm{R}^{2}$ & $\begin{array}{c}\text { B } \\
\text { Unstandardized }\end{array}$ & $\begin{array}{c}\text { B } \\
\text { Standardized }\end{array}$ & $\mathrm{p}$ \\
\hline Overall Model & .372 & & & .000 \\
\hline \multicolumn{5}{|l|}{ Coefficients: } \\
\hline Intercept & & .706 & & .007 \\
\hline Gender & & .010 & .005 & .941 \\
\hline Basic RN Education: & & -.116 & -.109 & .094 \\
\hline Years of Experience & & .001 & .017 & .797 \\
\hline \multicolumn{5}{|l|}{ Clinical Area: } \\
\hline Non-intensive care to intensive care & & -.209 & -.197 & .005 \\
\hline Other to intensive care & & .008 & .005 & .942 \\
\hline Internalized Sexism & & .234 & .343 & .000 \\
\hline Minimization of Self & & .288 & .333 & .000 \\
\hline
\end{tabular}




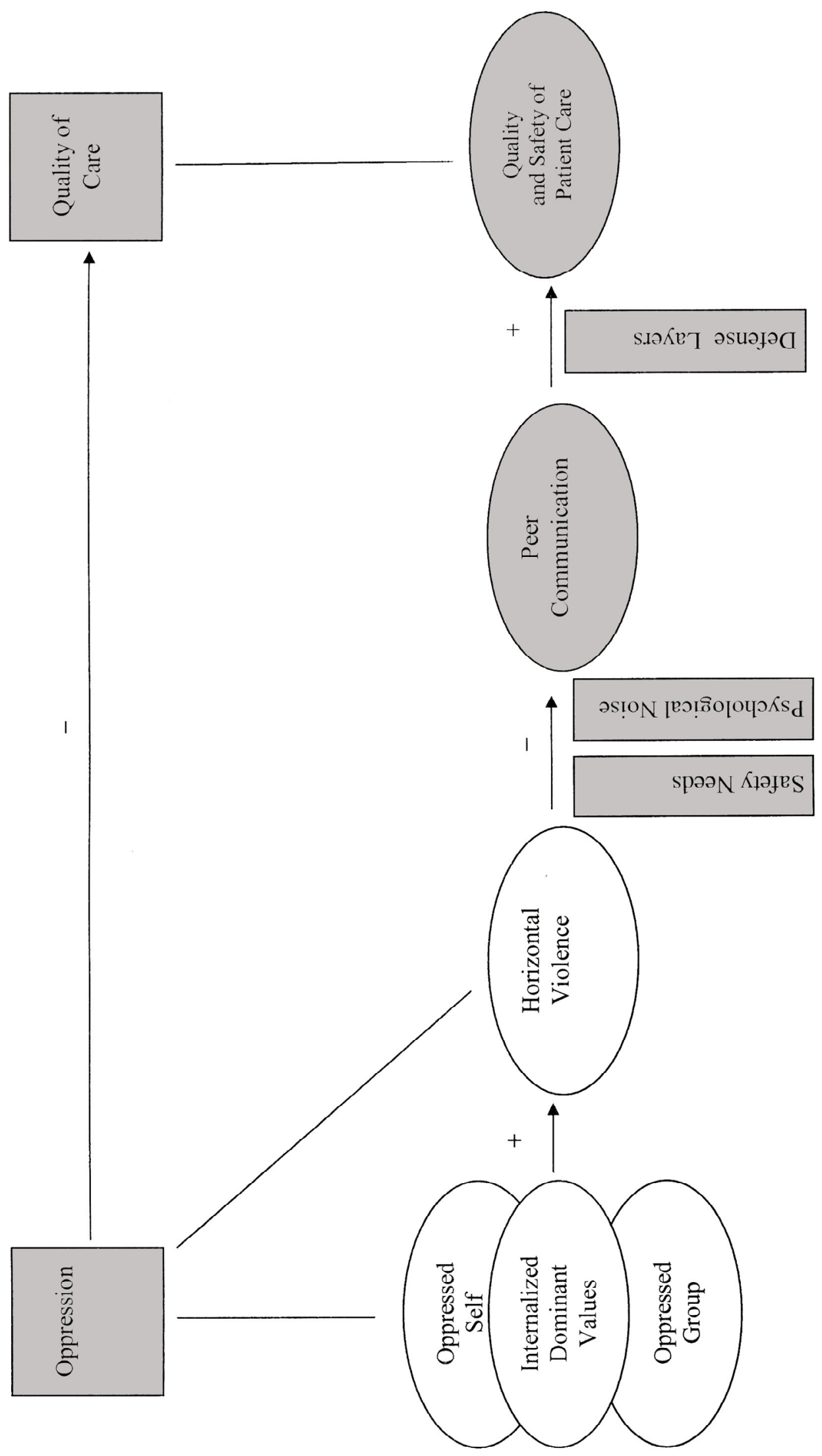

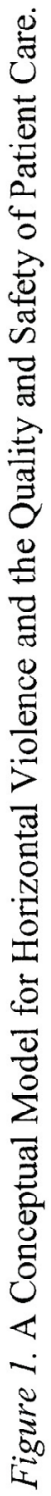

